\title{
O debate ecumênico em torno do Primado do Papa a partir da Carta Encíclica Ut Unum Sint
}

Geraldo Luiz Borges Hackmann

O presente artigo se propõe a analisar o debate ecumênico ocorrido entre as Igrejas Ortodoxa e Evangélico-luterana sobre o primado do Papa da Igreja Católica romana, como resultado da proposta que o Papa João Paulo II fez na Carta Encíclica Ut Unum Sint, de 25 de maio de 1995, no número 95:

"Mas tudo isto deve realizar-se sempre na comunhão. Quando a Igreja Católica afirma que a função do Bispo de Roma corresponde à vontade de Cristo, ela não separa esta função da missão confiada ao conjunto dos Bispos, também eles 'vicários e legados de Cristo'. O Bispo de Roma pertence ao seu 'colégio', e eles são os seus irmãos no ministério.

Aquilo que diz respeito à unidade de todas as Comunidades cristãs, entra obviamente no âmbito das preocupações do primado. Como Bispo de Roma, sei bem - e confirmei-o na presente Carta encíclica - que a comunhão plena e visível de todas as Comunidades, nas quais em virtude da fidelidade de Deus habita o seu Espírito, é o desejo ardente de Cristo. Estou convicto de ter a este propósito uma responsabilidade particular, sobretudo quando constato a aspiração ecumênica da maior parte das Comunidades cristãs, e quando ouço a solicitação que me é dirigida para encontrar uma forma de exercício do primado que, sem renunciar de modo algum ao que é essencial da sua missão, se abra a uma situação 
nova. Durante um milênio, os cristãos estiveram unidos pela 'fraterna comunhão da fé e da vida sacramental. Quando entre eles surgiam dissensões acerca da fé ou da disciplina, era a Sé de Roma quem, de comum acordo, as resolvia'.

Desse modo, o primado exercia a sua função de unidade. Dirigindo-me ao Patriarca Ecumênico, Sua Santidade Dimítrios I, disse estar consciente de que, 'por razões muito diferentes, e contra a vontade de uns e outros, o que era um serviço pôde manifestar-se sob uma luz bastante diversa. Mas (...) é com o desejo de obedecer verdadeiramente à vontade de Cristo que eu me reconheço chamado, como Bispo de Roma, a exercer este ministério (...). O Espírito Santo nos dê a sua luz, e ilumine todos os pastores e os teólogos das nossas Igrejas, para que possamos procurar, evidentemente juntos, as formas mediante as quais este ministério possa realizar um serviço de amor, reconhecido por uns e por outros"”.

O texto citado faz duas afirmações relevantes que merecem ser comentadas: A primeira diz respeito ao papel do Papa, enquanto sucessor do apóstolo Pedro, como elo de comunhão de toda a Igreja e, por isso, de se tornar também centro de unidade de todas as Comunidades cristãs. A segunda observação é quanto a iniciativa do próprio Papa João Paulo II: pede que pastores e teólogos encontrem juntos uma "forma de exercício do Primado" capaz de se tornar esse elo de comunhão, abrindo- se a uma "situação nova". É verdade que o Papa acrescenta "sem renunciar de modo algum ao que é essencial a sua missão". Mas esse aposto não significa exclusão ou limitação, mas quer retratar a tradição comum vigente no primeiro milênio do cristianismo, como conclui o número citado da Carta Encíclica.

É verdade que o tema do primado já havia sido objeto de diálogos ecumênicos anteriores à Ut Unum Sint. Já havia acontecido um Simpósio, em 1989, promovido pela Pontifícia Comissão de Ciências Históricas. Contudo, à luz dessa proposta, organizaram-se Simpósios para estudar como o primado do Papa poderia encontrar uma forma de exercício a fim de tornar-se um elo de unidade entre as Comunidades Cristãs. Assim, foram organizados dois Simpósios após a publicação da Encíclica: o primeiro, em 1996, em Roma, promovido pela Congregação para a Doutrina da Fé; o segundo, de 21 a 24 de maio de 2003, também em Roma, promovido pelo Pontifício Conselho para a Unidade dos Cristãos.

Esses dois Simpósios tiveram por objetivo pôr em ação a proposta do Papa João Paulo II. Por essa razão, foram simpósios acadêmicos, com debate 
entre teólogos católicos, ortodoxos e luteranos. As conferências e os debates foram publicados ${ }^{1}$.

\section{O diálogo com a Igreja Ortodoxa ${ }^{2}$}

A instituição canônica do primado papal está organicamente integrada na tradição comum das Igrejas do Oriente e do Ocidente antes e, também, depois do grande Cisma de 1054. É verdade que a teologia ortodoxa e a católica romana explicam de modo diferente como o primado papal vem concebido no primeiro e no segundo milênio da vida da Igreja. A razão vem do modo diferente com que os teólogos católicos romanos e os ortodoxos interpretam os testemunhos oferecidos pelas fontes do primeiro milênio. Contudo, independente do tipo de interpretação, as fontes estão submissas ao critério da consciência eclesial e da prática coerente deste período.

Essa diferença de interpretação poderá, também, ser atribuída ao fato que a teoria do primado papal teve, após o Cisma de 1054, uma mudança substancial. Esta transformação explicaria as reações teológicas observadas no Oriente e no Ocidente, como sobressai da teologia das correntes reformadoras dos séculos XIV ao XVI (via sinodal, concílios reformadores, Reforma protestante). Esta aparece também nos debates e nas decisões tomadas neste campo pelo Concílio de Trento (1545-1563).

A posição da teologia ortodoxa pode ser abordada a partir dos três pontos seguintes:

\section{a) Origem dos patriarcados}

$\mathrm{Na}$ tradição canônica comum do primeiro milênio, a administração eclesial está indissoluvelmente ligada à estrutura sinodal de uma jurisdição administrativa. Assim, o sínodo provincial está intimamente lidado ao sistema metropolitano. Há o direito de ordenação (jus ordinandi) e o direito de julgamento (jus jurandi). O mais importante, na administração eclesial da época, é a ordenação dos bispos. O sínodo provincial escolhe, ordena e julga o metropolita e os bispos da província. Esta forma característica de autonomia administrativa da Igreja local, em vigor em cada província, é a base da noção canônica da autocefalia administrativa da Igreja local.

\footnotetext{
${ }^{1}$ Il primato Del successore di Pietro. Atti del Simposio Teologico (Roma, dicembre 1996). Roma: Libreria Editrice Vaticana1998; W. KASPER (ed.), Il ministero petrino. Cattolici e ortodossi in dialogo. Roma: Città Nuova, 2004.

${ }^{2}$ Este ponto é uma síntese do texto de Vlassios Phidas, Le Primat papal et la pentarchie patriarcale dans la tradition orthodoxe. W. KASPER (ed.), Il ministero petrino, p. 73-91.
} 
Diante dos atos arbitrários dos simpatizantes do arianismo, relativos à eleição e ao julgamento dos bispos ortodoxos, tornou-se necessário controlar o momento das decisões tomadas nos sínodos orientais para evitar a perseguição dos bispos ortodoxos. A tentativa anterior, do II Concílio Ecumênico, nos cânones 2 e 6, de submeter os metropolitas a uma autoridade mais ampla, não deu resultado. É por isso que o cânon 14 do Concílio de Antioquia e os cânones 3, 4 e 5 do Concílio de Sárdica introduziram os procedimentos extraordinários e temporários para controlar as decisões dos sínodos provinciais pelos metropolitas.

Assim, é criado o sistema patriarcal. Os metroplitas passam a estar submissos às cinco sedes patriarcas: Roma, Constantinopla, Alexandria, Antioquia e Jerusalém. Malgrado a aparição de algumas correntes visando impor a autoridade supra-metropolita destas sedes, que estão dotadas do primado de honra canonicamente garantidas (cânon 6 e 7 do I Concílio ecumênico, cânones 2 e 3 do II Concílio ecumênico e cânon 36 do II Concílio de Trullo, de 629, [em Constantinopla, convocado pelo imperador Justiniano II]), os metropolitas conservam uma certa autonomia administrativa até o IV Concílio ecumênico. Estas correntes visam impor uma autoridade suprametropolita quanto ao direito de ordenar e de julgar os bispos, e, por conseqüência, enfraquecem e, finalmente, abolem a autonomia administrativa dos metropolitas.

Já a partir do final do século IV, as sedes, que gozavam de uma grande autoridade, procuram alargar a sua jurisdição administrativa em detrimento da autonomia metropolitana. A primeira metade do século $\mathrm{V}$ testemunha que as sedes de Roma, Constantinopla, Alexandria, Antioquia e Jerusalém tentam muitas vezes avançar em reivindicações administrativas semelhantes. Isso termina por abolir a autonomia metropolitana e por consagrar o sistema patriarcal na administração eclesial. Quase todas as províncias metropolitanas estão submetidas à jurisdição supra-metropolita das sedes, das quais provém, por decisão conciliar, um primado de honra canônico. Exceto a imprecisão concernente da jurisdição no Ocidente do Bispo de Roma, o IV Concílio ecumênico regula as fronteiras administrativas da jurisdição canônica das sedes orientais.

Desse modo, a aparição da autoridade supra-metropolitana, que gozam as cinco sedes patriarcais investidas de um primado de honra canônico, reorganiza profundamente e redistribui o direito de ordenar e de julgar os bispos no seio da Igreja universal. A introdução da pentarquia dos patriarcas na administração da Igreja universal tem duas conseqüências: a) Os metropolitas são privados de sua autocefalia administrativa, mas conservam sua autonomia interna. Assim, embora a ordenação dos metropolitas diz respeito a 
sede patriarcal respectiva, a eleição e a ordenação dos bispos de cada província permanece sempre na competência canônica do sínodo provincial. b) $\mathrm{O}$ patriarca de cada um dos cinco patriarcados é reconhecido como a nova autoridade autocéfala na administração da Igreja universal. Assim, ao passo que ele mesmo é eleito e ordenado pelo sínodo patriarcal, ele exerce diretamente o direito de ordenar os metropolitas e, indiretamente, com a supervisão destes últimos, os bispos.

\section{b) Os primados de honra e a instituição patriarcal}

A autoridade extraordinária da Pentarquia dos patriarcas está baseada em dois princípios:

1) os primados de honra extraordinários;

2) a jurisdição supra-metropolitana quanto ao direito de ordenar e de julgar os bispos. Esta nova instituição relativiza toda outra forma de autocefalia administrativa local. Com efeito, jamais antes uma Igreja local adquiriu, por qualquer título que seja, todos os privilégios obtidos por uma sede patriarcal. Ela jamais foi considerada "igual em honra" às sedes patriarcais. É verdade que cada uma das sedes foi investida de um primado de honra garantido canonicamente por um concílio ecumênico e que ela tem uma função administrativa supra-metropolitana. Ora, a atribuição dos primados de honra não é estranho ao cuidado eclesial de salvaguardar a comunhão das Igrejas locais espalhadas no mundo na verdadeira fé e amor. Tanto pela sucessão ininterrupta da fé apostólica quanto pela radiação universal de sua vida eclesial, estas sedes patriarcais adquiriram uma grande autoridade no seio da Igreja universal.

A partilha jurisdicional das regiões territoriais não aboliu nem diminuiu em nada a função excepcional conferido às sedes honradas com um primado de honra canônico na Igreja universal. Ao contrário, essa partilha confirma a autoridade excepcional destas sedes, exercida independentemente de toda regulamentação administrativa. Por conseqüência, os primados de honra e sua respectiva ordem de precedência não pode ser ignorada no funcionamento da Pentarquia dos patriarcas, mesmo quando se trata de regular as questões administrativas. Com efeito, elas estão intimamente ligadas à sua estrutura e à manifestação canônica da consciência conciliar, tanto mais no seio da jurisdição patriarcal quanto na realização universal da Igreja de Deus.

O direito de apelo (ekkletou) é uma manifestação significativa na tradição canônica. Deste modo, a primeira sede (prima sedes) goza do direito canônico o direito de receber e julgar um recurso de casos fora de suas próprias fronteiras jurisdicionais, isto é, surgidas na vida da Igreja universal. 
Todo sistema administrativo funciona em base a este princípio, ou seja, sobre o elo íntimo entre o primado de honra da primeira sede e o direito de apelo. Os cânones 3, 4 e 5 do Concílio de Sárdica (343) exprimem claramente uma tal concepção referente a competência do bispo de Roma; isto independente de interpretação dada a esta tendência canônica.

Embora o Concílio de Sárdica não sobrepujou em importância os outros concílios locais reunidos no século IV, os seus cânones serviram como principal argumentação em favor do primado papal e influenciaram as relações entre as Igrejas do Oriente e do Ocidente. Com efeito, os cânones 3, 4 e 5 do Concílio de Sárdica são invocados desde o início do século V - junto com o cânon 16 do primeiro Concílio ecumênico - para fornecer um fundamento canônico ao primado eclesial reivindicado pela sede romana. Durante o cisma de Acácio (484-519), o Papa Gelásio I (492-496) os integrou organicamente à teoria do primado romano. Eles são sempre alegados em toda luta que opõe Roma à Constantinopla para sustentar canonicamente a supremacia da Antiga sobre a Nova Roma. Assim, parece evidente que o Concílio de Sárdica se reveste de uma importância particular para o Ocidente, sobretudo em razão dos cânones 3,4 e 5, pois se tornaram regras que muitos canonistas interpretam como uma base legal muito clara para fundamentar a prerrogativa da sede papal de julgar em apelo todos os bispos da Igreja. Há argumentos a favor desta posição, expostos pela bibliografia canônica, e há, também, sólidos argumentos contra ela ${ }^{3}$.

Convém ressaltar que o primado de honra não é um privilégio puramente honorífico, porque está associado a uma autoridade excepcional (singularis auctoritas) em vista a garantir a unidade da Igreja na verdadeira fé e na disciplina canônica.

\section{c) Compreensão do Primado por parte da Igreja Ortodoxa}

A consciência eclesial do Oriente compreende o primado papal no contexto da instituição canônica da Pentarquia. Com efeito, ela não pode suspeitar as fermentações acontecidas no Oriente, da qual nenhum documento oficial foi endereçado à Igreja do Oriente a respeito desse tema. Por outro lado, ela não pode aceitar as reivindicações do Papa sobre sua autoridade superior à sede de Constantinopla, porque as considera contrárias ao princípio canônico segundo o qual os cinco patriarcados possuem autoridade igual. Assim, a consciência da Igreja do Oriente, tal como ela se manifesta na tradição canônica e a prática eclesial coerente, sempre reconhece o papa de Roma como o primus inter pares na Pentarquia dos patriarcas. O cânon 3 do

\footnotetext{
${ }^{3}$ Os argumentos a favor e contra estão abordados em Id., p. 79-81.
} 
II Concílio ecumênico atribui ao bispo de Constantinopla o primado de honra "depois de bispo de Roma", dando-lhe o segundo lugar na hierarquia das sedes honradas com um primado similar.

É assim que a tradição canônica e a experiência eclesial ortodoxa concebem o verdadeiro papel da "primeira sede" e a autoridade da qual ela está investida no concílio ecumênico e nas relações canônicas entre os patriarcas da Igreja universal. Com efeito, todo reconhecimento da autoridade excepcional da sede papal que, no seio da Pentarquia, diz respeito à primeira sede, a Igreja Oriental sustenta que os cinco patriarcados exercem de uma igual autoridade na celebração do concílio ecumênico e na vida da Igreja (primus inter pares). Em compensação, a Igreja romana interpreta sua precedência no primado de honra como um primado de poder dentro ou fora do concílio ecumênico. Estas correntes se manifestam sistematicamente após o grande cisma (1054). A teologia escolástica e o sistema canônico (Decretum Gratiani) da Igreja ocidental desenvolveu a idéia de que a autoridade papal é superior a do concílio ecumênico. Ao contrário, a Igreja oriental sublinha que, de acordo com a tradição canônica, o concílio ecumênico possui uma autoridade superior a do Papa, mesmo a dos cinco patriarcados da Igreja Universal. A primeira interpretação submete, portanto, o concílio ecumênico à autoridade papal; a segunda, em compensação, submete o papa e os patriarcas à autoridade do concílio ecumênico.

Mesmo reconhecendo o papel canônico excepcional que concerne à prima sedis, a Igreja do Oriente considera que este papel, ligado a administração eclesial, é exercido unicamente no sistema conciliar. Desde então, ela interpreta sempre a relação "autoridade papal/concílio ecumênico" no contexto canônico da relação pentarquia patriarcal/concílio ecumênico. Com efeito, baseando-se nos critérios da tradição e da prática conciliar, o Oriente insiste na relação canônica papa/patriarcas, enquanto que as correntes canônicas ocidentais redefinissem a relação canônica em base "papa/corpo episcopal". Neste espírito, o Oriente considera que o papa goza somente as prerrogativas canônicas da prima sedis no sistema da Pentarquia patriarcal. Por outro lado, o Ocidente interpreta esta mesma autoridade à luz da doutrina, introduzindo a teoria de um ministério petrino especial para reivindicar uma relação direta entre bispo de Roma e o corpo episcopal inteiro da Igreja universal.

Neste contexto, a teologia patrística está sempre de acordo com a tradição canônica sobre o modo de agir do sistema conciliar e sobre a prática eclesial seguida durante o período dos concílios ecumênicos. Esta é a razão pela qual, até o cisma do século XI, a Igreja do Oriente concede ao Bispo de Roma honras extraordinárias, a seu título de patriarca do Ocidente e de primeiro entre os cinco patriarcas da Igreja. Na qualidade de patriarca do 
Ocidente, ele tem os mesmos direitos que os outros quatro patriarcas. $\mathrm{Na}$ qualidade, no entanto, de primeiro segundo a ordem das precedências na Pentarquia dos patriarcas, ele tem a função extraordinária de coordenar seus pares para fazer frente ao conjunto dos problemas graves de fé e de disciplina canônica que ameaçam a unidade da Igreja na comunhão de fé ou no vínculo de amor. Por esta razão é que Roma reage fortemente, quando Constantinopla contesta a exclusividade desta prerrogativa canônica pela adoção do cânon 28 do IV Concílio ecumênico.

Por conseguinte, a tradição canônica ortodoxa considera depois sempre o primado papal:

a) No quadro da eclesiologia eucarística relativa a relação entre a Igreja local e a Igreja universal, pois que a Igreja uma, santa, católica e apostólica se realiza plenamente como corpo de Cristo em todo lugar e em todo tempo, e que ela não é uma simples adição das Igrejas locais.

b) No quadro das prerrogaticas extraordinárias que dizem respeito à prima sedis na instituição canônica da Pentarquia patraircal, isto é, no quadro do sistema administrativo da Igreja, porque a tradição canônica rejeita toda relação direta do papa com o corpo episcopal da Igreja universal e considera que o primado papal pode se exercer na comunhão de fé e vínculo de amor entre as Igrejas locais.

c) No quadro do funcionamento da instituição conciliar, notadamente do concílio ecumênico, que exprime perfeitamente os privilégios da primeira sede na relação canônica entre a Pentarquia dos patriarcas e o Concílio ecumênico. A tradição canônica refuta, pelo contrário, toda problemática concernente a superioridade da autoridade papal ou de um patriarcado sobre a do Concílio.

d) A convergência sobre os critérios canônicos e conciliares, em vigor no primeiro milênio, constitui uma base confiável para se engajar em um diálogo construtivo sobre o fundamento do "ministério de Pedro" e sobre a função na vida da Igreja. Tudo o que não está atestado no primeiro milênio não possui pressupostos eclesiológicos e canônicos necessários para servir de ponto de partida ao diálogo.

A partir dessa posição, podem ser feitas as seguintes observações:

a) A instituição canônica do primado papal é comum à tradição oriental e a ocidental, seja antes que depois de 1054 .

b) Os cânones dos Concílios Ecumênicos não podem ser isolados de outros documentos e eventos acontecidos em torno aos concílios. Todavia, eles devem ser lidos e compreendidos em seu contexto. Os cânones não devem ser separados nem de seu quadro histórico nem de seu quadro teológico. 
c) É importante compreender a dimensão histórica e a temporalidade da vida da Igreja.

d) Neste sentido, se deve reconhecer que a Pentarquia não pode funcionar como um tempo, pois que as circunstâncias históricas são profundamente mudadas.

e) Resta a questão de determinar como seja possível, hoje, reinterpretar e reconfigurar a visão subjacente da Igreja como comunhão.

f) Não se pode jamais ser entendido, segundo a tradição ortodoxa, "primado de honra" somente como "primado honorífico", o que contraria o Novo Testamento e a tradição da Igreja. A "honra" era sempre referido a uma função particular ou responsabilidade. O "primado" encerrava deveres e direitos, ao menos o "direito de apelo".

g) Qualquer tipo de "primado" deve ser compreendido, além disso, no espírito do cânon 34 dos Apóstolos, que afirma que o primeiro (protos) não pode fazer nada sem os outros, mas que, analogamente, os outros não podem fazer nada sem o primeiro. Isso implica em uma verdadeira e própria autoridade de primeiro que, com a sua presença e participação, pode e deve determinar o funcionamento do corpo reunido.

h) Daí resulta parecer difícil afirmar que os concílios ecumênicos estão acima do "primeiro" ou primado, pois nenhum concílio pode agir validamente sem "o primeiro".

i) Foi sublinhado que a tradição ortodoxa conhece o conceito de primado, sem, todavia, fazer nenhuma referência direta ao ministério de Pedro. Diante disso, se pode perguntar se tal referência ao ministério petrino é necessário para dotar a Igreja de um real primado. Se a resposta é sim para os católicos e não para os ortodoxos, resta saber como será possível fazer coincidir essas duas posições ${ }^{4}$.

As discussões recentes sobre o primado na teologia ortodoxa giram em torno de dois temas fundamentais, divididas em dois grupos. Um grupo vê uma conexão entre o primado e a natureza da Igreja, apesar de considerálo para o bem da Igreja, fruto de uma necessidade eclesiológica e questão canônica, e não faz parte do ser da Igreja. O outro grupo defende a posição de que o primado faz parte do ser da Igreja, de caráter eclesiológica e não simplesmente de ordem canônica. Estes dois grupos, por essa razão, têm posições diferentes sobre a interpretação do primus inter pares e o primado de honra, como também sobre a existência de um primado universal ${ }^{5}$.

\footnotetext{
${ }^{4}$ Id., p. $90-91$.

${ }^{5}$ Cf. Joannis Zizioulas, Recent discussions on Primacy in orthodox theology. W. KASPER, Il ministero petrino, p. 249-267.
} 
O Papa Bento XVI, em um discurso à delegação do Patriarcado Ecumênico de Constantinopla, no dia 28 de junho do ano corrente, insiste na importância do diálogo empreendido com os ortodoxos sobre o primado petrino, fruto da convicção comum da importância de tal diálogo ${ }^{6}$.

\section{O diálogo com a Igreja Luterana ${ }^{7}$}

Desde a origem da Reforma, a questão da instituição divina do ofício do Papa e a sua indole constitutiva na Igreja foi um dos temas mais controvertidos entre Reformadores e teólogos católicos. Acrescente-se a questão da sucessão de Pedro pelos Bispos de Roma. Há exigência de uma reinterpretação teológica do papado que as Igrejas de tradição Evangélico-luterana colocaram como condição prévia a um possível reconhecimento do ministério papal nos encontros bilaterais entre luteranos e católicos. Uma primeira questão diz respeito à origem e a índole eclesial do ministério petrino. A origem significa pôr a questão da legitimação teológica e histórica do ministério petrino. Em outras palavras: é de direito divino ou só de direito humano o primado? Ele é necessário ou apenas conveniente?

O primeiro diálogo ecumênico oficial entre a teologia católica e os Reformadores se deu em torno da questão da origem e a necessidade do ministério de unidade do Papa na Igreja. O encontro foi marcado por posições muito rígidas. Segundo Antón, a questão girava, inicialmente, em torno da instituição divina, porque exigia uma intervenção especial de Deus e na história e ao aplicar a expressão à Igreja, era necessário que sua origem remontasse a Jesus Cristo e que, desde o início, ela estava equipada com tudo o que era necessário para exercer a sua função até o final dos tempos, o que levava a concluir que o ministério petrino estava sempre presente de alguma forma desde o início na Igreja ${ }^{8}$.

O prosseguimento do diálogo ecumênico sobre a origem e a natureza do primado se manifestou possível em torno de dois tópicos: a primeira, se ele é de direito divino ou de direito humano; a segunda, o ofício do Papa é um elemento constitutivo, ou seja, pertencente ao ser da Igreja, ou é uma estrutura de mera utilidade, ou seja, pertencente ao bem estar. Além disso, é preciso inserir a questão do primado na totalidade da Igreja e considerá-lo

\footnotetext{
${ }^{6}$ Cf. www.vatican.va/holy_father/benedict_xvi/speeches/2010/june/documents/hf_ben.

7 Sigo, neste ponto, o texto de Angel Antón, "Ministério Petrino" y/o "Papado" en el dialogo com las otras Iglesias cristianas: algunos puntos de convergencia y divergencia. Il primato del successore di Pietro, p. 386-453.

${ }^{8} I d .$, p. $406 \mathrm{~s}$.
} 
como uma estrutura ministerial da Igreja, evitando uma abordagem desligada da totalidade da eclesiologia?.

A questão passou a girar em torno de um iure divino e um iure humano. A tese da distinção entre a função presbiteral e episcopal é de direito humano, porque foi resultado de uma evolução histórica, enquanto a existência do ministério ordenado é de direito divino, porque remonta a Sagrada Escritura, é compartilhada pela maioria dos teólogos luteranos. A mesma posição leva a distinguir entre a instituição divina - o ser - e forma de sua realização - o como. É de instituição divina que exista um ministério da palavra e dos sacramentos, mas como ele é estruturado é de disposição humana, ou seja, é de índole meramente funcional ${ }^{10}$. Contudo, não se pode separar o como de uma estrutura ministerial de seu ser, pois este é inseparável daquele. Não existe um direito divino abstrato, separado de uma estruturação humana, só na lei, como se houvesse uma dicotomia entre ambos. A Igreja encontra na estrutura humana a realização histórica do direito divino, pois a Igreja é a realização histórica das disposições divinas, de sua graça e salvação.

Diversos documentos do diálogo evangélico-luterano e católicoromano apresentam uma nova posição. O primeiro é o chamado Relatório de Malta, de 1972. É um documento importante, porque é o primeiro documento bilateral internacional a abordar o tema com certa amplitude e, devido a isso, influenciou de modo decisivo outros documentos posteriores no diálogo intereclesial sobre tal tema.

O documento, além de expor a posição das duas Igrejas sobre o primado, afirma que, da parte luterana, nenhuma Igreja local pode isolar-se, por ser manifestação da Igreja Universal. Apesar de não haver consenso entre as duas Igrejas sobre a índole e a necessidade do primado para a Igreja, reconhece a importância de um serviço para a comunhão das Igrejas. Acrescenta, ainda, que há controvérsia entre as duas Igrejas sobre a necessidade do primado para a Igreja ou se ele representa apenas uma função entre outras possíveis, diante da configuração concreta, que pode ser muito variável, em relação às condições históricas contingentes. Contudo, é positivo que o documento qualifica a índole da função do primado como "serviço de comunhão para as Igrejas" e "sinal visível de unidade entre as Igrejas". Neste sentido, o ministério do Papa não é excluído e o primado de jurisdição deve ser entendido como serviço para a comunidade e como meio de unidade da Igreja, embora subordinado ao primado do Evangelho, através de uma reinter-

\footnotetext{
${ }^{9} \mathrm{Ib}$.

${ }^{10}$ Cf. ib., p. 409.
} 
pretação teológica e uma reestruturação prática. Este serviço pela unidade é um serviço à unidade da fé ${ }^{11}$.

Dois anos mais tarde, a Comissão oficial católico-luterana dos Estados Unidos afirma sua disponibilidade para aceitar o "ministério do Papa", sob a condição de detalhamentos posteriores. Essa afirmação encontra-se na declaração intitulada $O$ primado pontifício e a Igreja Universal ${ }^{12}$. Em 1978, a comissão publicou outra declaração: A autoridade magisterial e a infalibilidade na Igreja ${ }^{13}$. Em ambas há uma abordagem mais ampla, pois são expostos os fundamentos bíblicos, o desenvolvimento histórico, aspectos sistemáticos, a função magisterial e a infalibilidade na Igreja.

Entre os pontos significativos das duas declarações, encontram-se os elementos fundamentais de convergência: a necessidade e a índole de um "ministério universal de unidade" exercido pelo ofício do Papa, como meio de unidade e de ordem. Esta afirmação é muito significativa, ainda mais se levando em conta sua origem na missão dada a Pedro por Jesus Cristo. Como o Evangelho é universal, a declaração entende a função petrina como "uma forma particular de ministério exercido por uma pessoa, um responsável ou uma Igreja local com respeito à Igreja em sua totalidade". Mesmo admitindo que haja graus na participação por parte dos titulares dos ministérios, como bispos e patriarcas, afirma que o representante mais importante, do ponto de vista de duração e geográfico, é o Bispo de Roma. Assim, há consenso em torno da consideração da origem da função petrina no tempo e no espaço do Novo Testamento e ao desenvolvimento histórico, que chega a se identificar com o ministério de unidade entre as Igrejas exercido pelo Bispo de Roma. Essas são declarações significativas do ponto de vista do diálogo ecumênico entre as duas Igrejas.

Entre os problemas apontados, destaca-se a questão se o primado é de direito divino (ius divinum) ou fruto de um desenvolvimento histórico (ius humanum), ligado ao problema histórico da instituição do papado por parte de Cristo. Enquanto os católicos reconhecem que o papado se desenvolveu historicamente sob o influxo do Espírito Santo, tendo sua origem no Novo Testamento, os luteranos reconhecem um bom número de contribuições positivas dadas à vida da Igreja, apesar de terem criticado no passado a estrutura e o funcionamento do mesmo ${ }^{14}$.

11 G. CERETI e s. J. VOICU, Enchiridion Oecumenicum. Documenti del dialogo interconfessionali. Dialoghi locali 1931-1984. Bologna: Dehoniane: 1986, vol. 1, n. 66, p. 581-582.

12 G. CERETI e s. J. VOICU, Enchiridion Oecumenicum. Documenti del dialogo interconfessionali. Dialoghi locali 1965-1987. Bologna: Dehoniane: 1988, vol. 2, n. 66 e 67, p. 1354-1376.

${ }^{13} I d .$, p. $1277-1454$.

${ }^{14} I d .$, n. 7-8, p. 1359-1360. 
Para haver uma renovação das estruturas do papado, a fim de que o parado possa servir à Igreja, o documento de 1974 aponta ser necessário levar em conta três princípios, que são os seguintes: princípio da legítima diversidade, princípio da colegialidade e princípio da subsidiariedade. A partir daí, há a possibilidade de aproximação entre as duas Igrejas, visto que os luteranos reconhecem a necessidade de um ministério a serviço da unidade da Igreja universal ${ }^{15}$.

Entre os pontos que são convergentes do documento de 1974, encontra-se a afirmação de que a Igreja luterana está disposta a entender que o primado pontifício, renovado à luz do Evangelho, não se torna um obstáculo à reconciliação ${ }^{16}$. O documento de 1978 vai mais além ao afirmar que os luteranos declaram oficialmente que a fidelidade às confissões luteranas não abraçam a afirmação de que o Papa ou o papado atual é o anti-Cristo e que as polêmicas anti-papais devem ser substituídas por uma atitude de respeito e de amor $^{17}$.

Assim, a via do diálogo continua aberto e com perspectivas de avançar ainda mais, pois o caminho percorrido até o presente momento foi significativo e representou uma aproximação ímpar entre as duas Igrejas na questão do primado do Papa.

\section{Aspectos a serem levados em conta na continuidade do diálogo}

Para o prosseguimento do diálogo ecumênico sobre o primado do $\mathrm{Pa}$ pa é necessário levar em conta alguns aspectos. Entre esses, podem ser citados os seguintes:

a) Uma renovação do papado à luz do Evangelho. Os diálogos ecumênicos evidenciam a necessidade de buscar a compreensão do primado e a renovação do papado sempre "em conformidade com o Evangelho" 18 . Assim, à luz da Sagrada Escritura será possível uma justa distinção entre a "essência" e a "forma" da realização do papado.

b) Considerar a figura do Papa no contexto da Igreja e integrando-o no conjunto da eclesiologia, mantendo a única relação entre Papa e Igreja, não de forma justapostas, mas como relação. Isto levará a considerar o minis-

\footnotetext{
${ }^{15}$ Id., n. 23-25, p. 1369-1371.

${ }^{16} I d .$, n. 32, p. 1373.

${ }^{17}$ Id., n. 21, p. 1452.

${ }^{18}$ Angel Antón, p. 437.
} 
tério petrino como um serviço à comunhão das Igrejas, como vem sendo frisado nos diálogos ecumênicos ${ }^{19}$.

c) É preciso manter a relação entre as duas jurisdições: a do Papa e a dos Bispos, mantendo a especificidade de cada uma delas. Assim, não se pode defender uma visão unicamente "jurídica" do primado, mas inseri-lo na compreensão sacramental da Igreja, como o faz o Vaticano II.

d) A figura do Papa está definida pela doutrina do primado definida pelo Vaticano I e o ensinamento do episcopado formalizado pelo Vaticano II. Ambos os ensinamentos devem estar em perfeita compatibilidade ou coerência e coesão, em uma forma que poderia ser chamada de "colegialidade estruturada", com a exclusão do regime monárquico e da colegialidade indeterminada, sem referência ao primado petrino. Assim, a "colegialidade estruturada" determinaria a modalidade do exercício do ministério petrino, em todas as suas formas, no que toca o ministério do Papa e dos bispos e na relação com as outras Igrejas. Neste sentido, seriam levados em conta os princípios da legítima diversidade, da colegialidade e da subsidiariedade. Neste sentido, será necessário reler o Vaticano I à luz de toda a Tradição da Igreja e integrado nela ${ }^{20}$.

Concluindo, percebe-se que certo primado da Igreja de Roma e de seu Bispo no primeiro milênio é reconhecido em todas as partes da Igreja, mesmo que se no Oriente se tente explicá-lo como uma honra para com a antiga capital do Império ou como um fato da disciplina canônica, mais do que por seu fundamento apostólico e petrino.

Embora o caminho a ser percorrido no diálogo ecumênico sobre o Primado ainda seja longo, já há consenso em vários aspectos. Este consenso é sinal de que as Comunidades cristãs, particularmente as Igrejas Ortodoxa e Evangélico-Luterana, estão dispostas ao diálogo. Por isso, é preciso invocar o Espírito Santo para que continue a iluminar a todos os cristãos, a fim de que encontrem o caminho da unidade sobre o primado petrino e seus sucessores.

\section{Resumo}

O presente artigo aborda o diálogo ecumênico com as Igrejas Ortodoxa e Evangélico-Luterana sobre o primado petrino e o papado, a partir de dois Simpósios Teológicos sobre o tema, como resposta ao pedido expresso pelo Papa João Paulo II na Carta Encíclica Ut Unum Sint 95.

\footnotetext{
${ }^{19}$ Cf. Walter Kasper, Introduzione al tema ed ermeneutica cattolica dei dogmi del Concilio Vaticano I. W. KASPER, Il ministero petrino, p. 19.

${ }^{20} I d$., p. $20-21$.
} 
Palavras-chave: Primado, Papa João Paulo II, Ut Unum Sint, Diálogo Ecumênico.

\begin{abstract}
The present article deals with the ecumenical dialogue with the Orthodox Church and the Lutheran-Evangelist Church about Petrine primacy and popehood, starting from two Theological Symposiums about the theme, as an answer to the request expressed by the Pope John Paulo II in the Letter Encyclical Ut Unum Sint 95.
\end{abstract}

Keywords: Primacy, Pope John Paul II, Ut Unum Sint, Ecumenical Dialogue.

Geraldo Luiz, Borges Hackmann

Doutor em Teologia pela Pontifícia Universidade Católica do

Rio Grande do Sul

E-mail: gborgesh@pucrs.br

Artigo Recebido em 11/08/2010

Artigo Aprovado em 24/09/2010 